\section{IMPROVEMENT IN MACHINING PERFORMANCE OF INCONEL 718 WITH SOLID LUBRICANTS}

\author{
Sunil Kumara, Dilbag Singh ${ }^{b}$, Nirmal Singh Kalsib
}

aResearch Scholar I.K.G. Punjab Technical University, Jalandhar, 144603, Punjab, India

bDepartment of Mechanical Engineering, Beant College of Engineering and Technology, Gurdaspur, 143521, Punjab, India
Article history

Received

13 March 2018

Received in revised form

24 May 2018

Accepted

15 June 2018

Published online

5 October 2018

*Corresponding author

skumar_73@

rediffmail.com

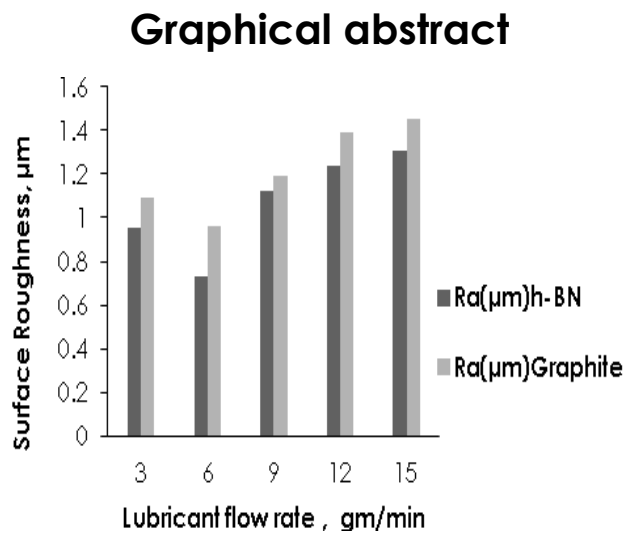

\begin{abstract}
From the last decade, the use of high corrosion resistance, high strength superalloys (mostly $\mathrm{Ni}$ - or Ti-based) at elevated temperature have significantly increased in aerospace or transport industry. Such materials are tremendously difficult to cut, develop a high temperature and deteriorate the quality of the components leading to tool wear. In place of using the cutting fluid, strict environmental limit develops new cutting methods or techniques for enhancing the tool life. This study demonstrates the performance of solid lubricants (hexagonal boron nitride and graphite) on surface quality. Tool geometry and cutting variables were selected for machining Inconel 718 with TiAIN-coated carbide inserts. The comparison has been conducted between solid lubricant assistant machining and dry machining. The studies demonstrate that the performance of solid lubricants is better than dry machining. There is $10 \%$ to $18 \%$ reduction in surface roughness with solid lubricants as compared to dry machining.
\end{abstract}

Keywords: Carbide inserts, Inconel 718, RSM, Surface roughness, Solid lubricants

(c) 2018 Penerbit UTM Press. All rights reserved

\subsection{INTRODUCTION}

The nickel-based Inconel 718 superalloy have excellent mechanical properties such as high oxygen resistance, high corrosion resistance and high strength to weight ratio. This high-class material mostly used for components of the gas turbine, pumps, aerospace engine, etc [1]. However, machining of the nickel-based alloy is tough due to its high work hardening tendency, small heat conduction and high chemical affinity with tool materials. It accelerates tool wear, develops poor surface quality and reduces productivity [2]. The formation of built-up edge and generation of heat at the cutting boundary of the tools are frequently observed. The high cutting force acting in the primary shearing zone promotes high friction with high generation of heat adversely affect the quality of component and accelerate the tool wear $[3,4]$.

For machining of such hard-to-cut superalloy, different techniques or methods have been developed by industries. These methods lower the temperature at the cutting region by using cutting fluids, tool materials, coatings and by some other sophisticated means. Application of conventional cutting fluid in machining process is the common practice. Cutting fluid is passed into the cutting zone which decreases the friction by lubrication to reduce the cutting temperature. Cutting fluids generate various troubles, like environmental pollution, water 
pollution and a medical problem to operators $[5,6]$. The used of cutting fluids also increase manufacturing cost [7].

Due to strict environmental limitation for the use of cutting fluids, researchers experimented some of the alternative approaches such as cryogenic coolant with liquid nitrogen, biodegradable coolants and solid lubricants in the cutting zone for reduction of friction and tool wear rate in all tribological conditions [8-11].

A possible solution is the application of minimum quantity lubrication (MQL) in machining such as vegetable oils, water based oils and synthetic lubricants. Hence, near dry machining (the use of minimum fluid, MQL) is appropriate for machining. While machining Inconel 718, these techniques have been applied by several researchers showing good results regarding reduction of tool wear and improving the surface integrity [12-14]. Lubricant delivered in the machining zone must be present at the chip-tool-work piece interface to form layers that reduced shear strength and friction. Such action of lubrication improves the tool life, surface quality and augments productivity. This practice has been broadly employed in several works performed in turning of Inconel 718, providing excellent results regarding better tool life and surface integrity [15]. According to Ezugwu et al. [16], nickel base alloys at high-speed conditions can be machined by a combination of the appropriate machining technique, tool material and the selection of a proper cooling method.

Another area of research, which also presents an environmental condition and has been used by several researchers is the area of machining with solid lubricants [17-19]. Solid lubricants can be applied in cutting zone to control the cutting temperature over a wide range. The use of various solid lubricants like graphite, boric acid, hexagonal boron nitride (white graphite), molybdenum disulfide and tungsten disulfide in machining have shown satisfactory results as regards the surface finish, cutting force and tool life. The right selection of solid lubricants decreases the product cost. Solid lubricants are also environmental friendly in nature.

Various studies are being conducted for green manufacturing with solid lubricants Du et al. [20] carried out an experimental investigation to study the effect of solid lubricants (molybdenum disulfide and graphite) on the surface roughness. Their finding revealed that the surface finish and environmental pollution had been significantly improved with solid lubricants. Mukhopadhyay et al. [21] observed that with the application of solid lubricants, the quality and the chip thickness were improved. Rao and Krishna [22] through their experimental work found that performance of solid lubricant was much better than dry and other, regarding a significant reduction in cutting forces, tool wear, and surface finish. Singh and Rao [23] have experimentally investigated the surface roughness of bearing steel with molybdenum disulfide as a solid lubricant. A significant enhancement of surface roughness was noticed with molybdenum disulfide as a solid lubricant compared to dry turning. Marques et al. [24] have studied the performance of solid lubricant mixed with oil when turning of Inconel 718 using cemented carbide tools. It was found that minimum quantity solid lubricant consisting of molybdenum disulfide and oil mixture performed better and improved machinability characteristics of Inconel 718. Paturi et al. [25] performed the solid lubricant assistant MQL machining of Inconel 718 with a statistical approach. Results showed that solid lubricants were more efficient in reducing the surface roughness.

Thus, from the published work, it is clear that solid lubricant acts as a coolant in machining operation is an alternative method for conventional machining, improves the performance. However, the combined effect of tool geometry and machining parameters such as approach angle, nose radius of the cutting tool, feed rate, cutting speed and application of solid lubricants have not been investigated in the machining of nickel-based superalloys Inconel 718 so far. This research aims to study the implementation of solid lubricants (graphite and hexagonal boron nitride) when turning of Inconel 718 with TiAlN-coated carbide tool. The parameter considered is surface roughness. The results that used graphite and hexagonal boron nitride solid lubricants were compared with dry machining under same working conditions.

\subsection{METHODOLOGY}

\subsection{Selection of Process Parameters}

In a machining process, the performance is measured in terms of cutting forces, surface finish and tool wear. The cutting parameters such as the type of coolant/lubricants, tool geometry have a significant effect on the surface quality. Surface quality during machining can be enhanced by selecting the appropriate combination of the process variables.

Table 1 Selected machining parameters and its levels

\begin{tabular}{lccccc}
\hline \multicolumn{1}{c}{ Actual Factors } & $\begin{array}{c}\text { Level } \\
\mathbf{1}\end{array}$ & $\begin{array}{c}\text { Level } \\
\mathbf{2}\end{array}$ & $\begin{array}{c}\text { Level } \\
\mathbf{3}\end{array}$ & $\begin{array}{c}\text { Level } \\
\mathbf{4}\end{array}$ & $\begin{array}{c}\text { Level } \\
\mathbf{5}\end{array}$ \\
\hline $\begin{array}{l}\text { Cutting speed, } \mathrm{v} \\
\text { (m/min) }\end{array}$ & 30 & 50 & 70 & 90 & 110 \\
$\begin{array}{l}\text { Feed rate, } \mathrm{f} \\
\text { (mm/rev) }\end{array}$ & 0.075 & 0.10 & 0.125 & 0.150 & 0.175 \\
$\begin{array}{l}\text { Approach angle, } \\
\text { a (degree) }\end{array}$ & 30 & 45 & 60 & 75 & 90 \\
$\begin{array}{l}\text { Nose radius, } \mathrm{r} \\
\text { (mm) }\end{array}$ & 0.2 & 0.4 & 0.8 & 1.2 & 1.6 \\
\hline
\end{tabular}

The cutting speed, feed rate, approach angle and the nose radius of the tool are considered as cutting conditions. Each parameter with five levels 
has been selected as shown in Table 1. A flow rate is fixed.

\subsection{Experimental Detail and Materials}

In this study, the surface roughness (Ra) has been selected as the response. Based on central composite design (CCD), 30 experiments were performed both with the dry condition and solid lubricants. Work piece material selected during experimentation was Inconel 718. Inconel 718 is having a hardness value of $37 \pm 1$ HRC. This material is used for aircraft components such as turbine disks and shafts. During experimentation, work pieces of 60 $\mathrm{mm}$ diameter (D) and $350 \mathrm{~mm}$ length (L) are selected to maintain L/D ratio less than ten as per ISO 3685 standards 1993 [26]. The chemical composition of Inconel 718 was as follows (wt \%): $53.50 \mathrm{Ni}$; $18.60 \mathrm{Cr}$; $2.95 \mathrm{Mo} ; 5.15 \mathrm{Nb} ; 17.30 \mathrm{Fe} ; 0.97 \mathrm{Ti} ; 0.19 \mathrm{Co} ; 0.59 \mathrm{Al}$; $0.024 \mathrm{~V} ; 0.140 \mathrm{Cu} ; 0.59 \mathrm{C}$ and other. A TiAlN-coated fine-grained high cobalt carbide with Grade KC5525 inserts (made by Kennametal) of different radii was selected. ISO designations of the inserts used were CNMG1204. ISO designation of tool holder was MCLNR2525M12. A depth of cut $0.2 \mathrm{~mm}$ was kept constant. The surface roughness value was calculated with a Mitutoyo made roughness tester (Surf test model No. SJ-400) with examined cut off length have a value of $0.8 \mathrm{~mm}$. The response result is the average of three measurements repeated three times equally positioned at $120^{\circ}$. Each experiment is performed with new cutting edge. Graphite and hexagonal boron nitride had been selected as solid lubricant for this study. The fine powder, $2 \mu \mathrm{m}$ average particle size was used. A setup was designed and developed.

Figures $1(a)$ and (b) indicate required experimental setup along with the flow rate of lubricant. The solid lubricating device has been designed to supply lubricant at $3 \mathrm{gm} / \mathrm{min}$ to 25 $\mathrm{gm} / \mathrm{min}$ which was fixed to the tool post. Figure 2 represents surface roughness variation with flow rate of solid lubricants (graphite and hexagonal boron nitride) at a speed of $70 \mathrm{~m} / \mathrm{min}$, feed of 0.125 $\mathrm{mm} / \mathrm{rev}$, approach angle of $60 \mathrm{deg}$ and $0.8 \mathrm{~mm}$ nose radius for a constant time. The result revealed that surface roughness varies with flow rate from 3 $\mathrm{gm} / \mathrm{min}$ to $15 \mathrm{gm} / \mathrm{min}$ with hexagonal boron nitride lubricant. The minimum surface roughness was observed at a flow rate of $6 \mathrm{gm} / \mathrm{min}$. Similar change has been analyzed for the other machining. Graphite powder showed the similar trend. Hence, $6 \mathrm{gm} / \mathrm{min}$ flow rate is satisfactory to attain the results with solid lubricant assisted machining. In this study, flow rate of $6 \mathrm{gm} / \mathrm{min}$ has been kept constant during the machining of Inconel 718 with graphite and hexagonal boron nitride powders (Figure 2). Response Surface Methodology (RSM) was used to develop the surface roughness models. The objective of this research is to investigate the outcome of these parameters on responses and consequently optimize these responses [27].

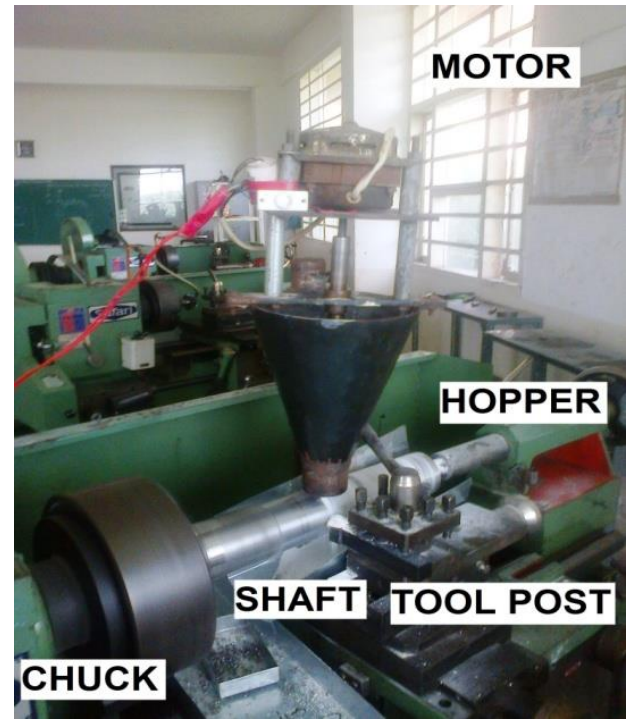

(a)

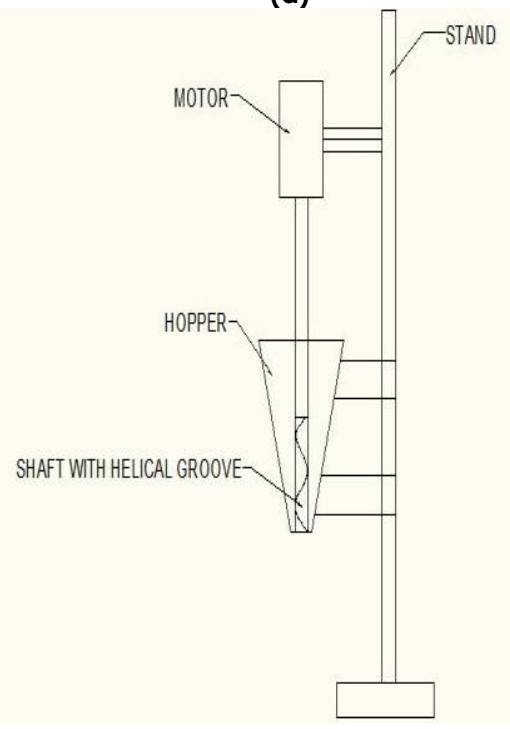

(b)

Figures 1 (a) Experimental Setup along with (b) solid lubricant equipment

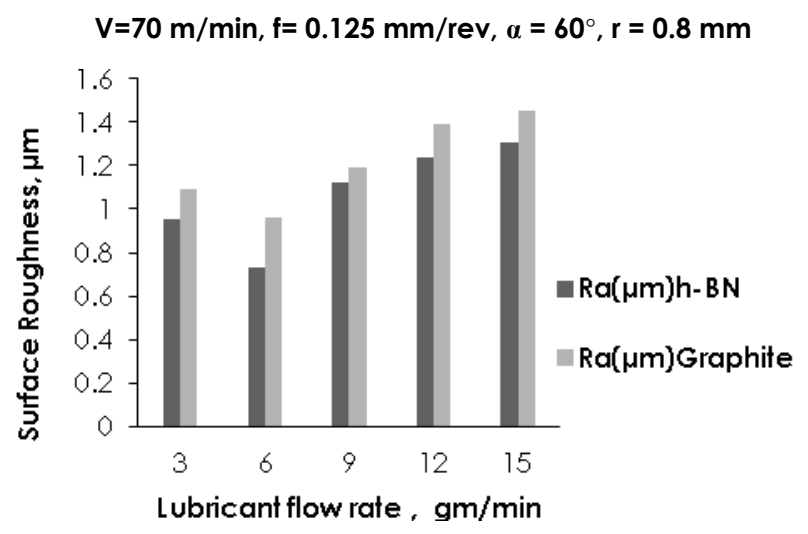

Figure 2 Variation of surface roughness with lubricant flow rate $(\mathrm{gm} / \mathrm{min})$ 


\subsection{Design of Experiment}

In the present experimentation, the second-order RSM-based mathematical models for surface roughness (Ra) were developed to emphasize the effect of process parameters $(v, f, a, r)$. In the current study, the relationship between cutting conditions and response can be expressed as follows:

$$
R a=\phi(v, f, a, r)+\epsilon
$$

Where Ra is the output (surface roughness), and $\phi$ is the response function. The approximation of surface roughness ( $R$ a) is proposed by using a quadratic mathematical model, which helps to study interaction effects of process parameters with response characteristics.

\subsection{RESULTS AND DISCUSSION}

\subsection{Surface Roughness Analysis}

During machining, being low thermal conductivity of Inconel 718, generation of heat develops high temperature at the machining zone and leads to poor surface quality. Hence, the overall improvement of the process requires the cutting zone temperature to be managed within the acceptable limits.

Table 2 ANOVA for surface roughness (graphite-assisted machining)

\begin{tabular}{|c|c|c|c|c|c|c|c|}
\hline $\begin{array}{c}\text { Sour } \\
\text { ce }\end{array}$ & SS & df & MS & $F_{\text {cal }}$ & $\mathbf{F}_{.05}$ & \multicolumn{2}{|l|}{$\begin{array}{c}\% \\
\text { con }\end{array}$} \\
\hline Mod & & & & & & & \\
\hline el & 2.97 & 11 & 0.27 & 132.15 & & & S \\
\hline v & 0.28 & 1 & 0.28 & 139.02 & 4.18 & 9.4 & $S$ \\
\hline$f$ & 0.38 & 1 & 0.38 & 189.84 & 4.18 & 12.8 & $S$ \\
\hline a & 0.42 & 1 & 0.42 & 210.28 & 4.18 & 14.2 & $S$ \\
\hline$r$ & 0.96 & 1 & 0.96 & 474.89 & 4.18 & 32.2 & $S$ \\
\hline$v^{*} a$ & 0.04 & 1 & 0.04 & 20.08 & 4.18 & 1.36 & $S$ \\
\hline$v^{*} r$ & 0.03 & 1 & 0.03 & 14.57 & 4.18 & 0.96 & $S$ \\
\hline$f^{*} a$ & 0.03 & 1 & 0.03 & 13.74 & 4.18 & 0.93 & $S$ \\
\hline $\mathrm{V}^{2}$ & 0.36 & 1 & 0.36 & 179.72 & 4.18 & 12.1 & $S$ \\
\hline$f^{2}$ & 0.10 & 1 & 0.10 & 50.97 & 4.18 & 3.4 & $S$ \\
\hline$a^{2}$ & 0.39 & 1 & 0.39 & 191.63 & 4.18 & 13.0 & $S$ \\
\hline$r^{2}$ & 0.36 & 1 & 0.36 & 178.42 & 4.18 & 12.1 & $S$ \\
\hline $\begin{array}{l}\text { Lack } \\
\text { of Fit }\end{array}$ & 0.03 & 13 & $\begin{array}{c}0.00 \\
2\end{array}$ & 2.56 & 2.98 & 1.06 & $S$ \\
\hline Pure & & & & & & & \\
\hline Error & 0.004 & 5 & 0.00 & & & & \\
\hline Cor & & & & & & & \\
\hline Total & 3.004 & 29 & & & & & \\
\hline
\end{tabular}

$s=$ significant, NS = Non significant
Thus, in this study, solid lubricants (graphite and hexagonal boron nitride) were selected for proper lubrication and reduction of friction. The significance of the process parameters was done by performing analysis of variance (ANOVA). As the first order model was not suitable and therefore, the second order model was developed from experiment results.

Table 3 ANOVA for surface roughness (h-BN assisted machining)

\begin{tabular}{|c|c|c|c|c|c|c|c|}
\hline $\begin{array}{c}\text { Sour } \\
\text { ce }\end{array}$ & SS & df & MS & $F_{\text {cal }}$ & $F_{.05}$ & $\begin{array}{c}\% \\
\text { con }\end{array}$ & \\
\hline Mod & & & & & & & \\
\hline el & 3.03 & 11 & 0.27 & 146.31 & & & $S$ \\
\hline v & 0.31 & 1 & 0.31 & 164.61 & 4.18 & 10.0 & $S$ \\
\hline$f$ & 0.37 & 1 & 0.37 & 200.11 & 4.18 & 12.2 & $\mathrm{~S}$ \\
\hline a & 0.61 & 1 & 0.61 & 327.38 & 4.18 & 20.0 & $S$ \\
\hline$r$ & 0.90 & 1 & 0.90 & 479.90 & 4.18 & 29.4 & $\mathrm{~S}$ \\
\hline$v^{*} \mathrm{a}$ & 0.02 & 1 & 0.02 & 13.99 & 4.18 & 0.8 & $S$ \\
\hline$v^{*} r$ & 0.03 & 1 & 0.03 & 16.70 & 4.18 & 1.0 & $S$ \\
\hline$f^{*} a$ & 0.04 & 1 & 0.04 & 21.73 & 4.18 & 1.3 & $S$ \\
\hline $\mathrm{V}^{2}$ & 0.36 & 1 & 0.36 & 195.65 & 4.18 & 12.0 & $S$ \\
\hline$f^{2}$ & 0.10 & 1 & 0.10 & 53.54 & 4.18 & 3.2 & $\mathrm{~S}$ \\
\hline$a^{2}$ & 0.33 & 1 & 0.33 & 179.06 & 4.18 & 10.9 & $S$ \\
\hline$r^{2}$ & 0.29 & 1 & 0.29 & 158.42 & 4.18 & 9.7 & $S$ \\
\hline $\begin{array}{l}\text { Lack } \\
\text { of Fit }\end{array}$ & 0.03 & 13 & $\begin{array}{c}0.00 \\
2\end{array}$ & 2.33 & 2.98 & 0.81 & $S$ \\
\hline Pure & 0.00 & 5 & 0.00 & & & & \\
\hline Error & 4 & 5 & 09 & & & & \\
\hline Cor & & & & & & & \\
\hline Total & 3.07 & 29 & & & & & \\
\hline
\end{tabular}

The results of the ANOVA for surface roughness in a reduced quadratic model for graphite and hexagonal boron nitride solid lubricants are shown in Table 2 and 3 respectively. These tables show the percentage contribution of each parameter and their interactions. The significance of the process variables was taken at $95 \%$ and $99 \%$ confidence level. The F-value of the models in Tables 2 and 3 are 132.15 and 146.31 respectively. Both models are significant. The 2.56 and 2.33 are the Lack of Fit Fvalue given in Tables 2 and 3 . It implies that the Lack of Fit is not significant about the real error in both models. The performance of Inconel 718 under dry condition was reported in the earlier studies of the author [28]. Quadratic regressions modeled the relationship between parameters and the performance measures. The second order surface roughness model with graphite-assisted machining thus developed is represented below; 
$\mathrm{Ra}=7.069-0.060 * \mathrm{v}-12.712 * \mathrm{f}-0.070 * \mathrm{a}-2.282 * r$ $+0.00016 * v^{*} a+0.005^{*} v^{*} r-0.112 * f * a+0.0003^{*} v^{2}+97.983^{*} f^{2}$ $+0.0005 * a^{2}+0.857 * r^{2}$

The second order surface roughness model with hexagonal boron nitride assisted machining, thus it is developed as below;

$$
\begin{aligned}
& R a=6.596-0.058 * v-11.015 * f-0.062 * a-2.145 * r \\
&+0.00013^{*} v^{*} a+0.0055^{*} v^{*} r-0.135 * f^{*} a+0.0002 * v^{2} \\
&+96.525 * f^{2}+0.0005^{*} a^{2}+0.776 * r^{2}
\end{aligned}
$$

Eqs. (1) and (2) represent the functional relationship between process variables and surface roughness to analyze the performance of graphite and hexagonal boron nitride solid lubricants during machining. A coefficient of determination (R2) value for both models are 0.985 and 0.989 respectively. These models can be used to predict surface roughness Ra at the particular design points.
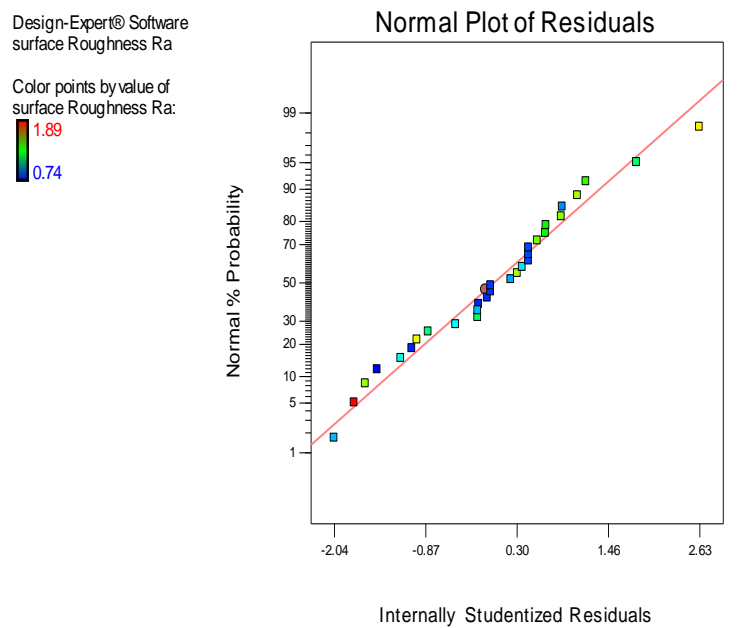

(a)

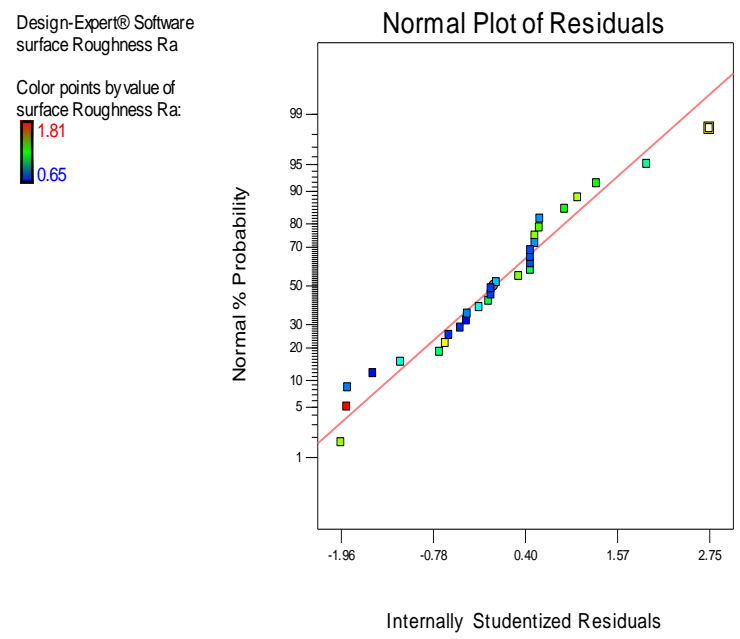

(b)

Figures 3 Normal plots of residuals (a) for graphite and (b) for hexagonal boron nitride solid lubricant

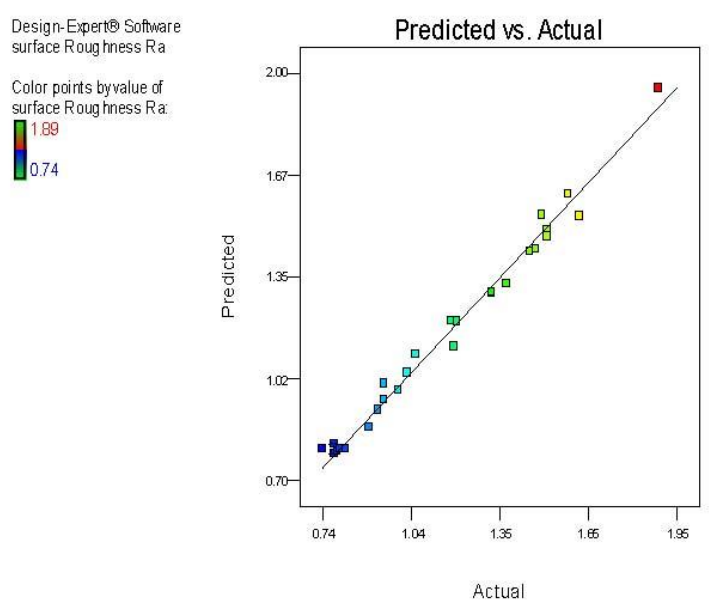

(a)

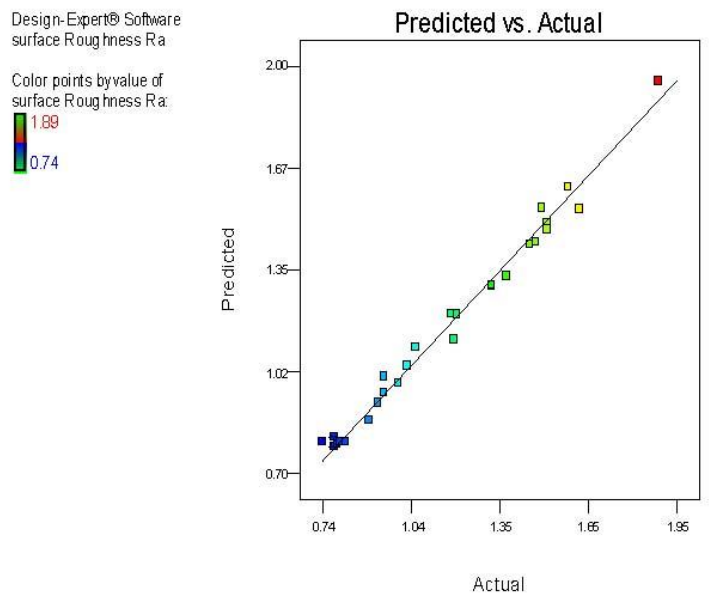

(b)

Figure 4 Comparison between experimental results and predicted value of surface roughness (a) for graphite and (b) for hexagonal boron nitride solid lubricant

Figure 3 (a) and (b) illustrate the normal probability plot of residuals for surface roughness $\mathrm{Ra}$ with graphite and hexagonal boron nitride solid lubricants. This plot shows that the data closely fall on the straight line which means the errors are normally distributed. The comparison between actual and predicted response for $\mathrm{Ra}$ with graphite and hexagonal boron nitride solid lubricants are illustrated in Figure 4 (a) and (b) respectively. The comparison indicated that predicted value of the surface roughness close to those readings recorded experimentally with a $95 \%$ confidence interval. This reflects the good agreement between experimental values and predicted values obtained with models shown in Eq. (1) and (2). 


\subsection{Effect of Cutting Speed}

Figure 5 (a) represents the surface roughness variation with cutting speed. Results showed that less surface roughness was obtained with solid lubricants in comparison to dry machining. The lower values of surface roughness produced with solid lubricants have been attributed to their lamellar structure which can shear easily along the tool-chip interface. It also leads to less heat generation and frictional effects at the chip-tool interface, thus improve the surface quality. In Figure 5(a) surface roughness decreases with an increase of the cutting speed. It is because the time for chips to remain in contact with a cutting tool decreases with the increase of cutting speed. It further reduces the friction between chip-tool interfaces along with a decrease of surface roughness. However, surface quality decreases above $70 \mathrm{~m} / \mathrm{min}$ due to tool wear at high speeds. The performance of hexagonal boron nitride is better than graphite. Micrograph of the chip collected at cutting speed (70 m/min), feed (0.125 mm/rev), approach angle (60 deg) and nose radius $(0.8 \mathrm{~mm})$ for hexagonal boron nitride and graphite are shown in Figures 7 (a) \& (b). The micrograph of the chip surface shows continuous and very fine chips which indicate good surface quality. Moreover, low surface roughness was observed with hexagonal boron nitride. It is because hexagonal boron nitride is more effective in removal of heat from cutting zone as compared to graphite and controls the machining zone temperature, thereby enhancing surface quality.

\subsection{Effect of Feed Rate}

The surface roughness variation with feed rate is represented in Figure 5 (b). Surface roughness increases as feed rate increases. The increase of feed rate leads to vibration and generation of more heat and, therefore, contributing the high value of surface roughness. However, solid lubricants possess better quality than dry machining. Figure 7 (c) \& (d) indicate the micrograph of the chip collected with graphite and hexagonal boron nitride at the high feed $(0.175 \mathrm{~mm} / \mathrm{rev})$, medium cutting speed $(70$ $\mathrm{m} / \mathrm{min}$ ), approach angle (60 deg), nose radius $(0.8$ $\mathrm{mm}$ ) respectively. The micrograph indicates the segmented and saw tooth edged chips with golden brown colour at a high feed rate with an excessive amount of heat generation which deteriorates surface quality.

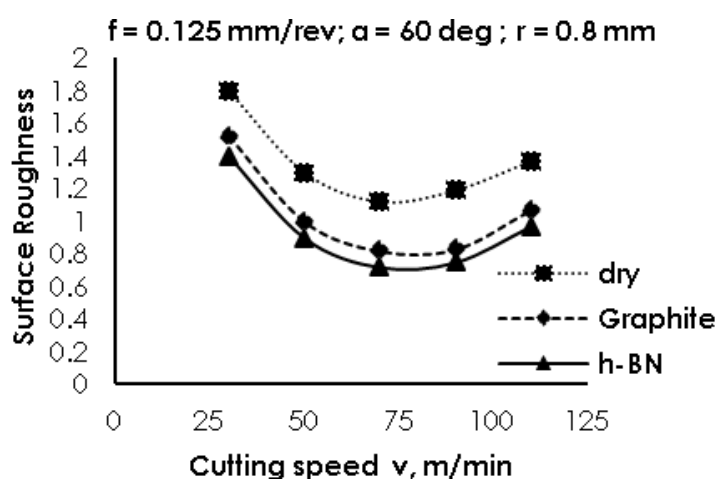

Figure 5 (a) Variation of surface roughness with cutting speed

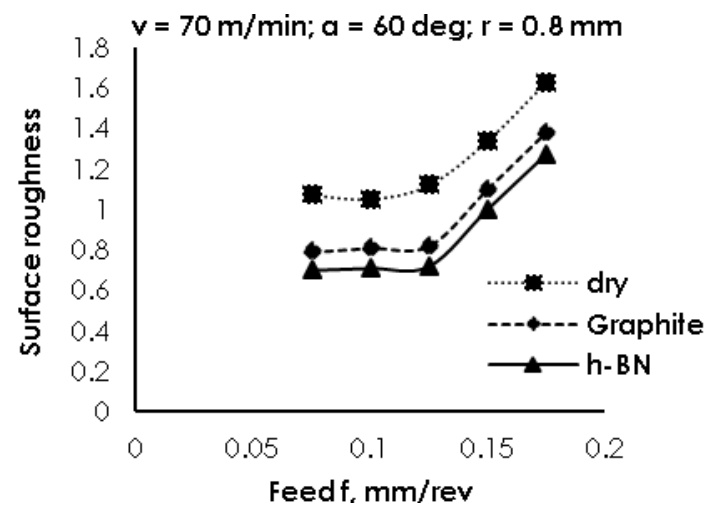

Figure 5 (b) Variation of surface roughness with Feed rate

\subsection{Effect of Approach Angle}

Figure 6 (a) represents the surface roughness variation with approach angle. With the increase of approach angle, the surface roughness initially decreases and grows up. At a small approach angle, the cutting edge is bigger which resulted to smaller chip thickness and favors low surface roughness. However, at a large approach angle, the cutting force is spread over a small section of the main cutting edge. The maximum cutting force is being at 90 deg approach angle rapidly in and out of cutting edge in the cutting zone. It is also subjected to maximum loading and unloading. Better surface quality was observed at 60-65 deg approach angle. Figure 7 (e) \& (f) represent the micrograph of the chip collected with graphite and hexagonal boron nitride at high approach angle (90 deg), medium cutting speed (70 m/min), feed $(0.125 \mathrm{~mm} / \mathrm{rev})$ and nose radius $(0.8 \mathrm{~mm})$. A continuous type of chip surface with small square shaped burr appeared resulting indicates poor surface finish. 


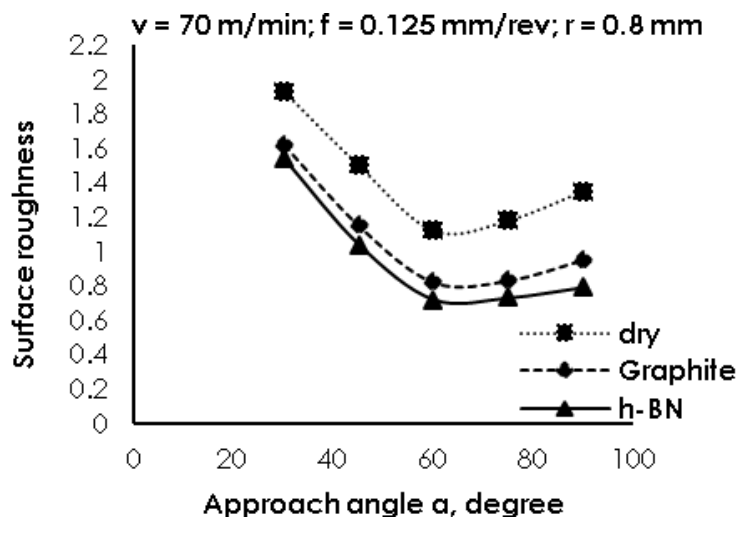

Figure 6 (a) Variation of surface roughness with approach angle

\subsection{Effect of Tool Nose Radius}

Surface roughness variation with nose radius is plotted in Figure 6 (b). Surface roughness decreases with the increase in tool nose radius from $0.2 \mathrm{~mm}$ to $1.0 \mathrm{~mm}$. At a tool radius of $0.2 \mathrm{~mm}$, high surface roughness is observed due to small contact area available for conduction of heat.

It increases the temperature along with the cutting edge that leads to poor surface quality. However, an increase in the value of surface roughness ( $\mathrm{Ra}$ ) is observed when tool nose radius changes from 1.0 to $1.6 \mathrm{~mm}$. This large nose radius is responsible for the large area of contact which causes chatter, vibration and high friction between tool and work piece interface resulting in an increase of surface roughness. Figure 7 (g) \& (h) reveal the micrograph of the chip collected for graphite and hexagonal boron nitride at higher nose radius (1.6 $\mathrm{mm})$, medium cutting speed $(70 \mathrm{~m} / \mathrm{min})$, medium feed rate $(0.125 \mathrm{~mm} / \mathrm{rev})$ along with medium value of approach angle $(60 \mathrm{deg})$. The micrograph indicates the formation of burr at chip surfaces which causes the decrease in surface quality.

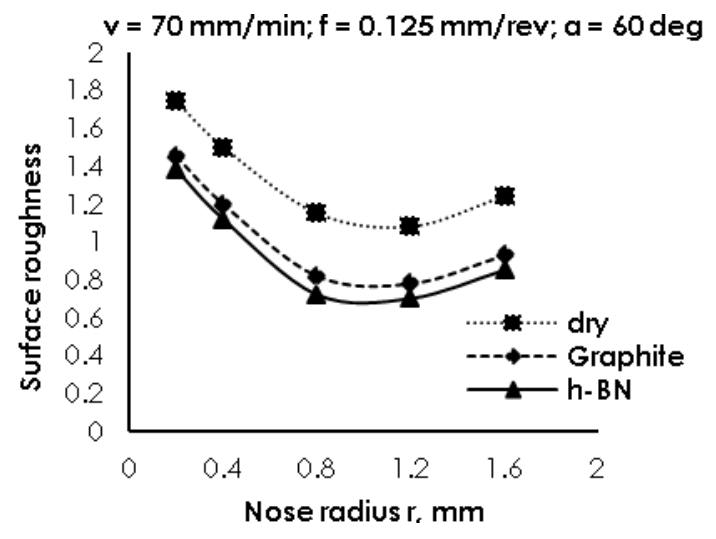

Figure 6 (b) Variation of surface roughness with nose radius
The plots have been observed from the above diagrams that show all environmental conditions represent similar trend during machining of Inconel 718. However, graphite and hexagonal boron nitride assisted machining resulted in lower values of surface roughness than dry. It is due to the inherent lubricating behavior of graphite and hexagonal boron nitride, which prolongs the tool life, thereby improving the surface quality. Between these two solid lubricants, hexagonal boron nitride yields has better surface quality due to its strong inherent lubrication properties as compared to the graphite. Hence, there is a reduction of $10 \%$ to $14 \%$ surface roughness values due to graphite and $15 \%$ to $18 \%$ due to hexagonal boron nitride.

\subsection{Optimization of Surface Roughness}

In this research, the optimization of cutting parameters for surface roughness is performed by summarizing the constraints. The results of RSM optimization process are presented in Table 4 in the order of decreasing desirability level. The optimal machining parameters for achieving 0.89 and 0.78 $\mu \mathrm{m}$ surface roughness while machining with graphite and hexagonal boron nitride solid lubricant are 100 $\mathrm{m} / \mathrm{min}$ cutting speed, $0.08 \mathrm{~mm} / \mathrm{rev}$ feed rate, $60 \mathrm{deg}$ approach angle and $1.20 \mathrm{~mm}$ nose radius.

Table 4 Response optimization for cutting force and temperature

\begin{tabular}{|c|c|c|c|c|c|}
\hline Solution. No. & 1 & 2 & 3 & 4 & 5 \\
\hline $\mathbf{v}$ & 100.0 & 100.0 & 100.5 & 100.8 & 100.5 \\
\hline$f$ & 0.08 & 0.08 & 0.08 & 0.08 & 0.08 \\
\hline a & 60.0 & 60.5 & 60.3 & 60.0 & 60.8 \\
\hline$r$ & 1.20 & 1.20 & 1.19 & 1.18 & 1.16 \\
\hline $\mathbf{R a}^{*}$ & 0.89 & 0.88 & 0.88 & 0.90 & 0.91 \\
\hline $\mathrm{Ra}^{* *}$ & 0.78 & 0.78 & 0.80 & 0.79 & 0.81 \\
\hline Desirability & 0.987 & 0.986 & 0.985 & 0.984 & 0.983 \\
\hline Remarks & Selected & & & & \\
\hline
\end{tabular}

\subsection{CONCLUSION}

The present research work was conducted to observe the surface quality of Inconel 718 with TiAINcoated carbide tools. Solid lubricants were compared with dry machining. Response surface methodology (RSM) method was used to find the adequacy and the relationship between input and output response. Further surface roughness was evaluated through the graphs. Additionally, a micrograph of chips was analyzed and determined 
at different conditions. Finally, the RSM optimization process for achieving minimum surface roughness was performed using the desirability function approach. Following conclusions were observed from the experiment.

The quadratic model was selected for both response parameters, namely for graphite and hexagonal boron nitride solid lubricants. It was shown that there was a good agreement between experimental and predicted values by quadratic models. Solid lubricant hexagonal boron nitride provided better surface quality than graphite and dry condition while machining of Inconel 718 with TiAlN-coated carbide tools. So, this methodology offers considerable benefits regarding surface finish and environmental pollution over other methods of machining Inconel 718.

Nose radius, approach angle and feed rate had a significant effect on the surface roughness. Additionally, nose radius with a percentage contribution of $32.25 \%$ and $29.47 \%$ was the most important factor during machining with solid lubricants. Based on optimization process, the optimum cutting variables for minimum surface roughness were cutting speed of $100 \mathrm{~m} / \mathrm{min}$, feed rate of $0.08 \mathrm{~mm} / \mathrm{rev}$, approach angle of $60 \mathrm{deg}$ and $1.20 \mathrm{~mm}$ nose radius. The optimized surface roughness parameter, $\mathrm{Ra}$ is 0.89 and $0.78 \mu \mathrm{m}$ for graphite and hexagonal boron nitride solid lubricants.

This experimental investigation helped in explaining the chip micrograph of Inconel 718 during

\section{Conditions}

$\mathrm{v}=70 \mathrm{~m} / \mathrm{min}$

$\mathrm{f}=0.125 \mathrm{~mm} / \mathrm{rev}$,

$a=60 \mathrm{deg}$

$\mathrm{r}=0.8 \mathrm{~mm}$

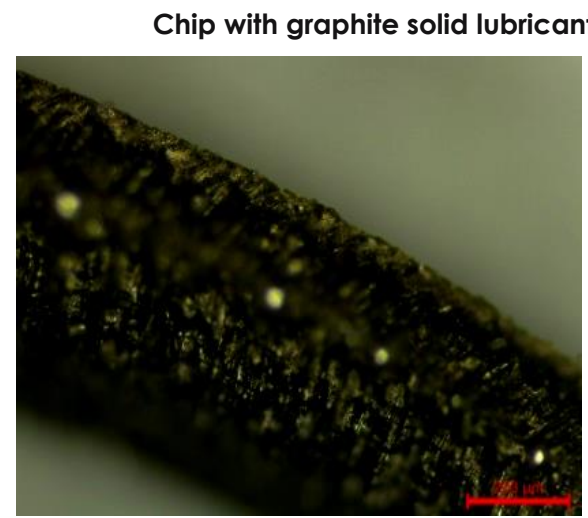

(a)

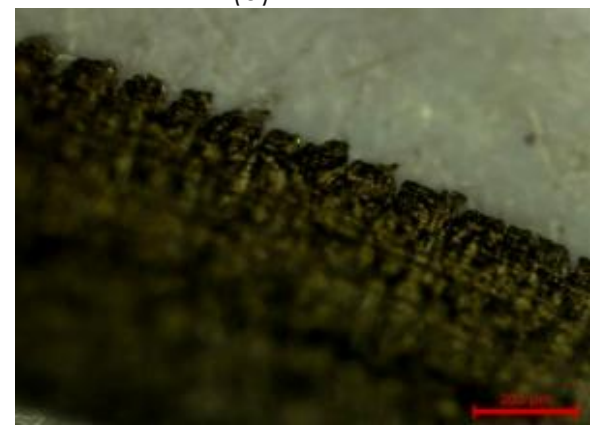

(c) machining under various cutting environment, which will give valuable knowledge to manufacturers in proper selection of cutting parameters. It is also predicted that proper selection of solid lubricant, cutting conditions and tool geometry is vital for achieving the overall performance.

\section{ACKNOWLEDGEMENT}

The author is highly thankful to the IKG Punjab Technical University, Kapurthala (Punjab), India for his support in the research area.

$\begin{array}{ll} & \text { APPENDIX } \\ \text { Notation } & \\ v & \text { Cutting Speed }(\mathrm{m} / \mathrm{min}) \\ \mathrm{f} & \text { Feed Rate (mm/rev) } \\ \mathrm{a} & \text { Approach Angle (degree) } \\ \mathrm{r} & \text { Tool Nose Radius }(\mathrm{mm}) \\ \mathrm{Ra} & \text { Surface Roughness }(\mu \mathrm{m}) \\ \mathrm{h}-\mathrm{BN} & \text { Hexagonal boron nitride }\end{array}$

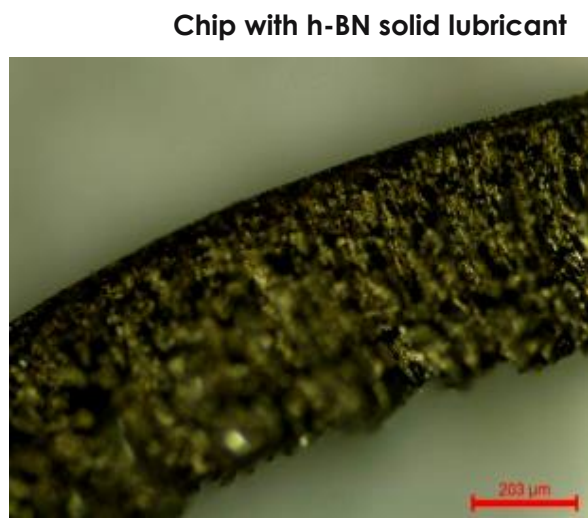

(b)

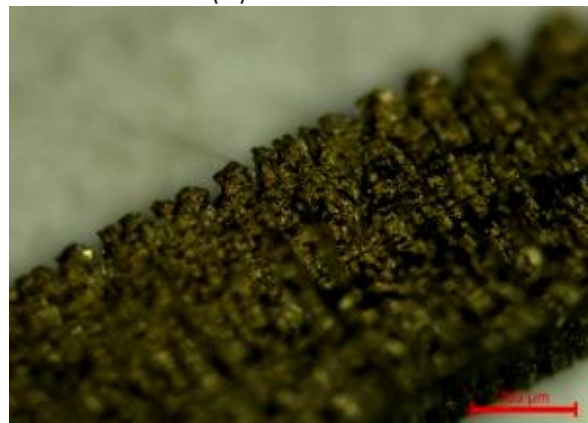

(d) $v=70 \mathrm{~m} / \mathrm{min}$,

$\mathrm{f}=0.175 \mathrm{~mm} / \mathrm{rev}$,

$a=60 \mathrm{deg}$,

$\mathrm{r}=0.8 \mathrm{~mm}$ 
$\mathrm{v}=70 \mathrm{~m} / \mathrm{min}$,

$\mathrm{f}=0.125 \mathrm{~mm} / \mathrm{rev}$,

$a=90 \mathrm{deg}$

$\mathrm{r}=0.8 \mathrm{~mm}$

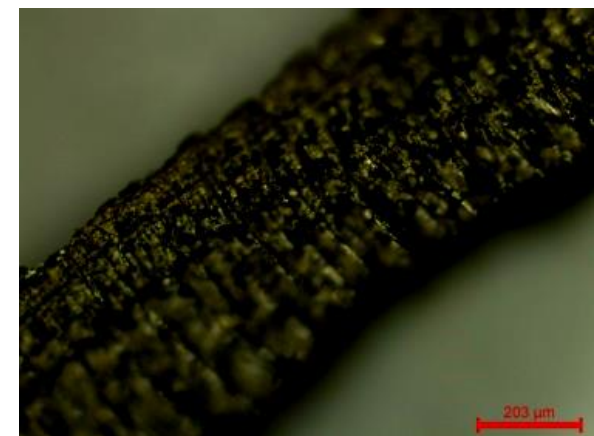

(e)

$v=70 \mathrm{~m} / \mathrm{min}$,

$\mathrm{f}=0.125 \mathrm{~mm} / \mathrm{rev}$,

$a=60$ deg,

$\mathrm{r}=1.6 \mathrm{~mm}$

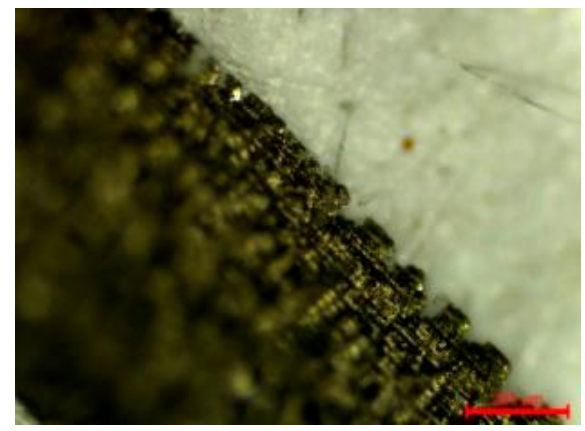

(g)

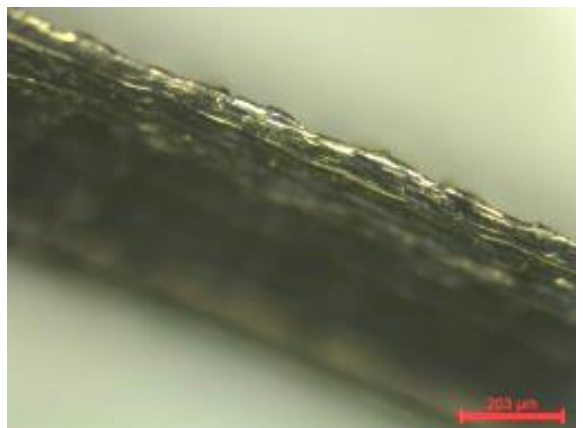

(f)

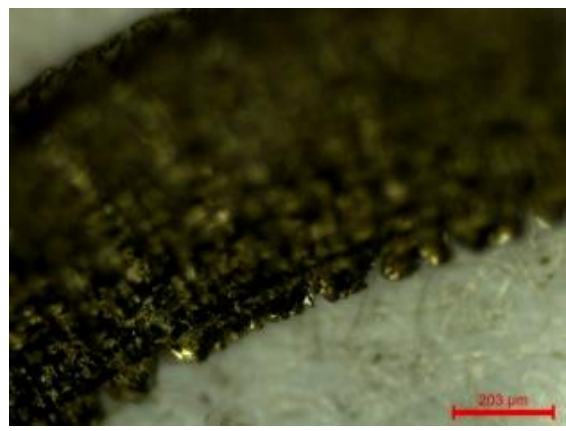

(h)

Figure 7 Micrograph of chip collected (100X) at various conditions

\section{References}

[1] Choudhury, I. A. and El-Baradie, M. A. 1998. Machining Nickel Base Superalloys: Inconel 718. Proceedings of the Institution of Mechanical Engineers, Part B: Journal of Engineering Manufacture. 212(3): 195-206. doi.org/10.1243/0954405981515617.

[2] Dudzinski, D., Devillez, A., Moufki, A., Larrouquere. D., Zerrouki, V. and Vigneau, J. 2004. A Review of Developments Towards Dry and High Speed Machining of Inconel 718 Alloy. International Journal of Machine Tools and Manufacture. 44(4): 439-456. doi.org/10.1016/S08906955(03)00159-7.

[3] Ezugwu, E., O., Wang, Z. M. and Machado, A. R. 1999. The Machinability of Nickel-based Alloys: A Review. Journal of Materials Processing Technology. 86(1): 1-16. doi.org/10.1016/S0924-0136(98)00314-8.

[4] Dudzinski, D., Devillez, A., Moufki, A., Larrouquere, D., Zerrouki, V. and Vigneau, J. 2004. A Review of Developments Towards Dry and High Speed Machining of Inconel 718 Alloy. International Journal of Machine Tools and Manufacture. 44(4): 439-456. doi.org/10.1016/\$08906955(03)00159-7.

[5] Suresh Kumar Reddy, N. and Nouari, M. 2011. The Influence of Solid Lubricant for Improving Tribological Properties in Turning Process. Lubrication Science. 23(2): 49-59.

[6] Suresh Kumar Reddy, N. and Venkateswara, Rao. P. 2005 Performance Improvement of End Milling Using Graphite as a Solid Lubricant. Materials and Manufacturing Processes. 20(4): 673-686. doi.org/10.1081/AMP-200055036.

[7] Sreejith, P. S. and Ngoi, B. K. A. 2000. Dry Machining: Machining of the Future. Journal of Materials Processing Technology. 101(1): 287-291. doi.org/10.1016/S09240136(00)00445-3.

[8] Sharman, A. R. C., Hughes, J. I. and Ridgway, K. 2008. Surface Integrity and Tool Life When Turning Inconel 718 Using Ultra-High Pressure and Flood Coolant Systems. Proceedings of the Institution of Mechanical Engineers,
Part B: Journal of Engineering Manufacture. 222(6): 653664. doi.org/10.1243/09544054JEM936.

[9] Thirumalai, R., Senthilkumaar, J. S., Selvarani, P. and Ramesh S., 2013. Machining Characteristics of Inconel 718 Under Several Cutting Conditions Based on Taguchi Method. Proceedings of the Institution of Mechanical Engineers, Part C: Journal of Mechanical Engineering Science. 227(9): doi.org/10.1177/0954406212466193.

[10] Magri, A., Diniz, A. E. and Suyama, D. I. 2016. Evaluating the Use of High-pressure Coolant in Turning Process of Inconel 625 Nickel-Based Alloy. Proceedings of the Institution of Mechanical Engineers, Part B: Journal of Engineering Manufacture. 0954405416664373. doi.org/10.1177/0954405416664373.

[11] Kiliçay, K. and Ulutan. M. 2016. Investigation of the Solid Lubrication Effect of Commercial Boron-based Compounds in End Milling. International Journal of Precision Engineering and Manufacturing. 17(4): 517-524. doi.org/10.1007/s12541-016-0065-1

[12] Paturi, U. M. R. and Narala, S. K. R. 2015. Experimental Investigation to Study the Effect of Electrostatic MicroSolid Lubricant-coated Carbide Tools on Machinability Parameters in Turning. Proceedings of the Institution of Mechanical Engineers, Part B: Journal of Engineering Manufacture. doi.org/10.1177/0954405414530903.

[13] Marques, A., Narala, S. K. R., Machado, A. R., Gunda, R. K., Josyula, S. K., DaSilva, R. B. and DaSilva, M. B. 2015. Performance assessment of MSQL: Minimum quantity solid lubricant during turning of Inconel 718. Proceedings of the Institution of Mechanical Engineers, Part B: Journal of Engineering Manufacture. 0954405415592128.

[14] Rahim, E. A., Ibrahim, M. R., Rahim, A. A., Aziz, S. and Mohid, Z. 2015. Experimental Investigation of Minimum Quantity Lubrication (MQL) as a Sustainable Cooling Technique. Procedia CIRP. 26: 351-354. doi.org/10.1016/j.procir.2014.07.029.

[15] Yazid, M. Z. A., Che Haron, C. H., Ghani, J. A., Ibrahim, G. A. and Said, A. Y. M. 2011. Surface Integrity of Inconel 718 
when Finish Turning with PVD Coated Carbide Tool under MQL. Procedia Engineering. 19: 396-401.

[16] Ezugwu, E. O., Bonney, J. and Yamane, Y. 2003. An Overview of the Machinability of Aeroengine Alloys. Journal of Materials Processing Technology. 134(2): 233253. doi.org/10.1016/S0924-0136(02)01042-7.

[17] Rahmati, B., Sarhan, A. A. and Sayuti, M. 2014. Morphology of Surface Generated by End Milling AL6061T6 Using Molybdenum Disulfide (MOS 2) Nanolubrication in End Milling Machining. Journal of Cleaner Production. 66: 685-691. doi.org/10.1016/j.jclepro.2013.10.048.

[18] Reddy, N. S. K., Nouari, M. and Yang, M. 2010. Development of Electrostatic Solid Lubrication System for Improvement in Machining Process Performance. International Journal of Machine Tools and Manufacture. 50(9): 789-797. doi.org/10.1016/j.jimachtools.2010.05.007.

[19] Reddy, N. S. K. and Rao, P. V. 2006. Experimental Investigation to Study the Effect of Solid Lubricants on Cutting Forces and Surface Quality in End Milling. International Journal of Machine Tools and Manufacture. 46(2): 189-198 doi.org/10.1016/j.jijmachtools.2005.04.008.

[20] DU, G., CHEN, Y. and Wei, Z. 2012. Effects of Solid Lubricants on Hard Turning. 2nd International Conference on Electronic \& Mechanical Engineering and Information Technology. Atlantis Press.

[21] Mukhopadhyay, D., Banerjee, S. and Reddy, N. S. 2007. Investigation to study the Applicability of Solid Lubricant in Turning AISI 1040 Steel. Journal of Manufacturing Science and Engineering. 129(3): 520-526.
[22] Rao, D. N. and Krishna, P V. 2008. The Influence of Solid Lubricant Particle Size on Machining Parameters in Turning. International Journal of Machine Tools and Manufacture. 48(1): 107-111. doi.org/10.1016/j.jimachtools.2007.07.007.

[23] Singh, D. and Rao, P V. 2008. Improvement in Surface Quality with Solid Lubrication in Hard Turning. Proceedings of the World Congress on Engineering. 3: 2-4

[24] Marques, A., Narala, S. K. R., Machado, A. R., Gunda, R. K., Josyula, S. K., DaSilva, R. B. and DaSilva, M. B. 2015. Performance Assessment of MSQL: Minimum Quantity Solid Lubricant during Turning of Inconel 718. Proceedings of the Institution of Mechanical Engineers, Part B: Journal of Engineering Manufacture. 0954405415592128.

[25] Paturi, U. M. R., Maddu, Y. R., Maruri, R. R. and Narala, S. K. R. 2016. Measurement and Analysis of Surface Roughness in WS2 Solid Lubricant Assisted Minimum Quantity Lubrication (MQL) Turning of Inconel 718. Procedia CIRP. 40: 138-143.

[26] International Organization for Standardization. Tool-Life Testing with Single Point Turning Tools ISO 3685-1993 (E), 2nd Edition; ISO Genève, Switzerland.

[27] Montgomery, C. D. 1997. Montgomery Design and Analysis of Experiments. John Wiley.

[28] Kumar, S., Singh, D. and Kalsi, N. S. 2015. Some Investigations on Machining of Nickel based Super Alloy using Coated Carbide Inserts. Proceedings of the $17^{\text {th }}$ ISME Conference on Advances in Mechanical Engineering. 